Check for updates

Cite this: RSC Adv., 2018, 8, 30115

Received 8th July 2018

Accepted 14th August 2018

DOI: $10.1039 / \mathrm{c} 8 \mathrm{ra05825c}$

rsc.li/rsc-advances

\title{
Synthesis and characterization of an efficient and stable Al/Fe pillared clay catalyst for the catalytic wet air oxidation of phenol $\dagger$
}

\begin{abstract}
John Moma, (D) *a Jeffrey Baloyi ${ }^{\mathrm{ab}}$ and Thabang Ntho ${ }^{\mathrm{b}}$
A facile method for synthesizing Al/Fe pillared clays (PILCs) from natural bentonite clay, by using ultrasonic treatment during the aging and intercalation steps, has been established. Single metal (Fe-PILCs and AlPILCS) and mixed metal (Al/Fe-PILCs, with varying compositions of the pillaring precursors) pillared clays were prepared and characterized with a combination of chemical and instrumental methods. The pillared clays were evaluated as catalysts in the catalytic wet air oxidation (CWAO) of phenol and the mixed metal pillared clay catalysts, especially with an Al/Fe ratio of $3: 1$, were found to be highly active and stable, with superior properties such as surface areas, basal spacing, high porosity and thermal stability. The catalysts could also be reused several times without significant loss of activity. The results of the study show that Al/Fe-pillared clay catalysts are effective catalysts for the oxidation of phenol and removal of TOC in aqueous solutions. The main intermediate products in the CWAO of phenol were hydroquinone, pyrocatechol, and benzoquinone and oxalic, formic, malonic, oxalic, malonic and maleic acids.
\end{abstract}

\section{Introduction}

In recent times, a lot of research efforts have been dedicated to the development of efficient new 'green' technologies such as advanced oxidation processes (AOPs) for the removal of organic refractory pollutants from industrial effluents. Among several AOPs, the catalytic wet air oxidation (CWAO) using oxygen as the oxidative agent over a catalyst to initiate non-selective oxidation of refractory organic pollutants appears to be the most promising due to its effectiveness in converting organic compounds in industrial pollutants to $\mathrm{CO}_{2}$ and $\mathrm{H}_{2} \mathrm{O} .{ }^{1}$ The CWAO process is economic and environmentally friendly and more suitable for organic pollutants which are too dilute to be incinerated and too concentrated to be treated by a biological process. ${ }^{1}$ CWAO is a green process which can operate at mild temperatures and pressures in the presence of a highly active catalyst, which positively influences the economics of the wastewater treatment operations.

However, the CWAO process has several drawbacks which limit its industrial application. These include the lack of stable, highly active and low cost catalysts (without noble metals). Therefore, a lot of research effort has been focused on the

${ }^{a}$ Molecular Sciences Institute, School of Chemistry, University of the Witwatersrand, Johannesburg, South Africa. E-mail: john.moma@wits.acza

${ }^{b}$ Advanced Materials Division, MINTEK, 200 Malibongwe Drive, Randburg 2125, South Africa

$\dagger$ Electronic supplementary information (ESI) available. See DOI: $10.1039 / \mathrm{c} 8 \mathrm{ra} 05825 \mathrm{c}$ development of an active and robust catalyst, which can reduce the severity of the reaction conditions of the CWAO process, making it a possible commercial technology., ${ }^{2,3}$ Clay minerals modified by pillaring have recently been found as potential catalytic materials for removal of refractory organic pollutants in wastewater. The clay minerals are abundant in nature, cheap and environmental friendly. The modification by pillaring involves intercalation of large polyoxocation in the interlayer space of the natural clay, which improves thermal and mechanical stability, porosity and BET surface area, basal spacing and accessibility to its acid sites. ${ }^{1,4-6}$ The intercalation of clays using polyoxocation solutions containing two cations has been reported to improve thermal stability and catalytic properties. ${ }^{7,8}$

Nevertheless, the synthesis of pillared inter-layered clays (PILCs) using the conventional method has drawbacks such as prolonged synthesis times and high water consumption. This makes the pillaring process not economically scalable to industrial production. Therefore, the use of advanced green chemistry synthesis methods such as microwave radiation and ultrasound treatment has gained considerable attention with many studies aimed to reduce time and energy costs. ${ }^{9}$ Timofeeva et al. reported that the micropore volume and the overall surface area of Al-PILCs can be affected by degree of hydrolysis of a pillaring solution $(0.5<\mathrm{OH} / \mathrm{Al}<2.5)$ and the optimum $\mathrm{OH} /$ metal ratio was 2.2. ${ }^{10}$ They discussed in details the effects of $\mathrm{OH} /$ $(\mathrm{Fe}+\mathrm{Al})$ ratio, aging time of $\mathrm{Fe}$, and $\mathrm{Al}$ containing pillaring solution on physicochemical properties of Fe, Al-pillared clays. Shin et al. ${ }^{11}$ observed the increase in total surface area, 
micropore area and pore volume with aging time of the $\mathrm{Al}_{13^{-}}$ solution because of the transformation of $\mathrm{Al}_{13}{ }^{7+}$ into $\mathrm{Al}_{24} \mathrm{O}_{72}$ $\left(\mathrm{Al}_{13}\right.$ dimer $)$ and other polyoxocation. Gil et al. ${ }^{12}$ reported that the higher $\mathrm{Al} / \mathrm{Fe}$ and $\mathrm{OH} /(\mathrm{Al}+\mathrm{Fe})$ ratios, the larger the amount of $\mathrm{Al} / \mathrm{Fe}$ polyoxocation that forms in solution. $\mathrm{Al} / \mathrm{Fe}-\mathrm{PILCs}$ have been used in many studies as an effective catalyst in oxidation of phenol and chlorophenol in water by catalytic wet oxidation using hydrogen peroxide as oxidant. ${ }^{13-16}$ Very limited studies have investigated the use of PILCs in the CWAO process using oxygen as oxidant, taking into account the drawbacks of the synthesis methods of the pillaring agents solutions., ${ }^{1,3}$ Consequently, up to date, there is still great research interest to develop novel synthesis methods for PILCs that are economically viable. Ultrasonic treatment during the synthesis procedure has been reported to significantly reduce the synthesis time as well as water consumption. Numerous studies reported the use of ultrasound treatment method during aging of the pillaring solution and intercalation to decrease the synthesis time as well as the volume of water used in the pillaring process by approximately by $95 \% .^{\mathbf{9}, 17,18}$

Therefore, this study, Al/Fe-PILCs catalysts were synthesized using ultrasound treatment by direct addition of natural bentonite clay into the polyoxocation solutions containing $\mathrm{Al}$ and Fe metals followed by intercalation through ion exchange. The Al/Fe-PILCs were tested for CWAO of phenol in aqueous solutions. Finally, the catalyst stability and its regeneration were also investigated.

\section{Materials and method}

\subsection{Materials}

Bentonite clay was obtained from ECCA Holdings (Pty) Ltd., (Cape Town, South Africa). The natural bentonite clay was used without any further purification or cation exchange, sieving or refining. Analytical grade $\mathrm{NaCl}, \mathrm{Na}_{2} \mathrm{CO}_{3}, \mathrm{Al}\left(\mathrm{NO}_{3}\right)_{3} \cdot 9 \mathrm{H}_{2} \mathrm{O}$, $\mathrm{Fe}\left(\mathrm{NO}_{3}\right)_{3} \cdot 9 \mathrm{H}_{2} \mathrm{O}, \mathrm{HCl}$ and $\mathrm{NaOH}$ were obtained from Merck Chemicals (Pty) Ltd. Phenol was obtained from Sigma Aldrich Chemical Co. Analytical-grade hydroquinone, benzoquinone, catechol, oxalic acid, acetic acid, maleic acid, malonic acid and formic acid used to prepare standards intermediates solutions were also purchased from Sigma-Aldrich Chemical Co. Acetic acid and methanol of chromatographic grade was obtained from Merck.

\subsection{Preparation of $\mathrm{Al} / \mathrm{Fe}$ pillared bentonite clay}

2.2.1 Preparation of pillaring solutions. The Al pillaring solution was prepared by dropwise addition of $\mathrm{NaOH}$ solution $(0.4 \mathrm{M}, 500 \mathrm{~mL})$ into a solution of $\mathrm{Al}\left(\mathrm{NO}_{3}\right)_{3}(0.4 \mathrm{M}, 250 \mathrm{~mL})$ under vigorous stirring. After continuous stirring for $120 \mathrm{~min}$, the resulting solution was ultrasonicated at room temperature for $10 \mathrm{~min}$. The Fe pillaring solution was also prepared by dropwise addition of $\mathrm{NaOH}$ solution $(0.4 \mathrm{M}, 500 \mathrm{~mL})$ into a solution of $\mathrm{Fe}\left(\mathrm{NO}_{3}\right)_{3}(0.4 \mathrm{M}, 250 \mathrm{~mL})$ solution under vigorous stirring, followed by the same procedure as above. The mixed $\mathrm{Al} /$ Fe pillaring solutions with different $\mathrm{Al} / \mathrm{Fe}$ molar ratios were prepared by slowly addition of $\mathrm{NaOH}(0.4 \mathrm{M})$ into a mixture of
$\mathrm{Al}\left(\mathrm{NO}_{3}\right)_{3}(0.4 \mathrm{M}, 250 \mathrm{~mL})$ and $\mathrm{Fe}\left(\mathrm{NO}_{3}\right)_{3}(0.4 \mathrm{M}, 250 \mathrm{~mL})$ solutions under vigorous stirring until an $\left[\mathrm{OH}^{-}\right] /\left[\mathrm{Al}^{3+}+\mathrm{Fe}^{3+}\right]$ molar ratio of $2: 1$ was reached. The concentrations used for the synthesis single and mixed pillared bentonite clay in this study was adapted from various literature reports. ${ }^{19-22}$ Then the resulting solution was ultrasonicated for $10 \mathrm{~min}$ to obtain the $\mathrm{Al} / \mathrm{Fe}$ pillaring agent solution.

2.2.2 Preparation of Al-PILCs, Fe-PILCs and Al/Fe-PILCs catalysts. The pillared clay catalysts were prepared from bentonite clay using ultrasonic treatment method according to the modified method described previously. ${ }^{18}$ The exchange process of the bentonite clay was carried out with each of the pillaring solutions of $\mathrm{Al}, \mathrm{Fe}$ or $\mathrm{Al}-\mathrm{Fe}(\mathrm{Al} / \mathrm{Fe}$ molar ratios of $1: 3$, $1: 1,3: 1$ and $6: 1$ ). The dry natural bentonite clay was added directly into pillaring solutions at a ratio of $25 \mathrm{~mL}$ of pillaring solution per gram of clay and vigorously stirred at $25{ }^{\circ} \mathrm{C}$ for $30 \mathrm{~min}$. The resulting suspension was ultrasonicated for $10 \mathrm{~min}$ at $25{ }^{\circ} \mathrm{C}$ to perform the ion exchange. The suspension was centrifuged and the solid component washed with high purity water (5 times each with $200 \mathrm{~mL}$ portions) to remove any unreacted nitrates. The solids obtained were oven-dried at $120{ }^{\circ} \mathrm{C}$ in air for 16 hours and calcined at $500{ }^{\circ} \mathrm{C}$ for $120 \mathrm{~min}$. The prepared PILCs samples were referred as Al-PILCs, FePILCs, Al/Fe-PILCs (1:3), Al/Fe-PILCs (1:1), Al/Fe-PILCs (3:1), Al/Fe-PILCs $(6: 1)$, respectively.

\subsection{Catalysts characterization}

The high-resolution scanning electron microscope (HRSEM) imaging and chemical analysis of the raw and PILCs samples were obtained using FEI Nova NanoSem 200. The chemical compositions of the samples were determined by semiquantitative energy dispersive X-ray (EDX) spectrometry using an Oxford INCA instrument (Oxford instruments, UK). Zetasizer (Malvern Instruments, UK) was used to obtain zeta potential values of the samples at different $\mathrm{pH}$ values in order to determine their points of zero charge $\left(\mathrm{pH}_{\mathrm{zpc}}\right)$. Cation exchange capacity (CEC) was determined using the Kjeldahl method described elsewhere. ${ }^{6} 0.2 \mathrm{~g}$ of each material was saturated with $1 \mathrm{M}$ ammonium acetate solution, followed by washing with methanol and five repeated washing with high purity water. The retained ammonium ions were then determined by the unit Kjeldahl method. The powder X-ray diffraction (PXRD) patterns of the samples were obtained from 5 to $80^{\circ}$ of $2 \theta$ range by a high resolution Bruker AXS D8 X-ray advanced powder diffractometer with CoK $\alpha$-radiation ( $40 \mathrm{kV}, 40 \mathrm{~mA}, 1.78897 \AA)$ using a LynxEye detector at scanning speed of $0.02^{\circ} \mathrm{s}^{-1}$. The basal spacing $\left(d_{001}\right)$ values were also determined using XRD patterns recorded. Isotherms of nitrogen adsorption-desorption of raw bentonite clay, Bt and PILCs were measured using the Micromeritics ASAP TriStar 3000 equipment. The samples were degassed under vacuum at $150{ }^{\circ} \mathrm{C}$ for $4 \mathrm{~h}$. The specific surface area $\left(S_{\mathrm{BET}}\right)$ of the samples were obtained by the BET method and the total pore volume $\left(V_{\mathrm{t}}\right)$ was calculated at a relative $\mathrm{N}_{2}$ pressure of $P / P^{0} \sim$ 0.99 , at liquid nitrogen temperature of $-196{ }^{\circ} \mathrm{C}$. Pore size distribution in the mesopore range was calculated using the Barrett-Joyner-Halenda (BJH) method based on the desorption 
arm of the isotherms. Fourier transform infrared (FTIR) spectroscopic data was determined using a Varian 640-IR FTIR spectrometer with a miracle single bounce diamond ATR (attenuated total reflectance) cell from PIKE Technologies. The FTIR spectra of the samples were recorded at $25{ }^{\circ} \mathrm{C}$ between the wavenumbers ranging from 400 to $4000 \mathrm{~cm}^{-1}$ with resolution of $4 \mathrm{~cm}^{-1}$. Thermogravimetric (TGA) analysis was carried out on simultaneous thermal analyser (STA) instrument (Perkin-Elmer model 6000) by heating about 5-10 $\mathrm{mg}$ of the samples under $\mathrm{N}_{2}$ flowing at $20 \mathrm{~mL} \mathrm{~min}{ }^{-1}$ at linear heating rate of $10{ }^{\circ} \mathrm{C} \mathrm{min}{ }^{-1}$ from $35{ }^{\circ} \mathrm{C}$ to $800{ }^{\circ} \mathrm{C}$.

\subsection{Catalytic wet air oxidation of phenol}

The catalytic activities of Al-PILCs, Fe-PILCs and Al/Fe-PILCs catalysts were investigated using the CWAO of phenol solution as a model pollutant through a continuously stirred highpressure stainless steel autoclave semi-batch reactor equipped with a magnetically driven stirrer. The initial $\mathrm{pH}$ of the phenol solutions was adjusted to the desired $\mathrm{pH}$ value of 3 by adding $1 \mathrm{M} \mathrm{NaOH}$ or $\mathrm{HCl}$ solutions prior to CWAO experiments. All experiments were performed at optimal values determined in our preliminary investigations as indicated in ESI (Fig. S3-S7 $\dagger$ ). The initial concentration of phenol solutions was prepared at $1000 \mathrm{mg} \mathrm{L}^{-1}$ and the amount of catalyst was $2 \mathrm{~g} \mathrm{~L}^{-1}$. The reactor content was stirred vigorously for about $60 \mathrm{~min}$ in the dark at the desired temperature prior to the reaction. The air in the reactor was removed by purging the reactor system with pure nitrogen three times before nitrogen pressure of 5 bars was maintained for $5 \mathrm{~min}$. The reactor content was heated to the desired temperature of $100{ }^{\circ} \mathrm{C}$ with the stirrer set at $800 \mathrm{rpm}$. Once the reactor content had reached the desired temperature, pure oxygen at the desired pressure at 10 bars was supplied to the reactor for the duration of the reaction. $5 \mathrm{~mL}$ samples were withdrawn periodically during the reaction and filtered using a micro filter of $0.45 \mu \mathrm{m}$ pore size prior to analysis. The phenol concentration in the liquid samples was determined using high performance liquid chromatography (HPLC) method with an ODS-3 column and a UV detector (LC-10AD, Shimadzu, Kyoto, Japan). A methanol/water mixture (60/40 v/v) was used as mobile phase. The flow rate of the mobile phase was $1 \mathrm{~mL} \mathrm{~min}^{-1}$. Total organic carbon (TOC) of the effluents was measured by a TOC analyzer to evaluate the mineralization degree in the CWAO of phenol. All experimental data analyses were conducted in triplicate, and the average values were used in the calculations.

\subsection{Catalyst stability and its reusability studies}

The metal leaching from the solid catalysts during CWAO of phenol reactions were determined by inductively coupled plasma-atomic emission spectrometer (ICP-AES) spectroscopy. The CWAO experiments were carried out in the same way as the main CWAO experiments at optimal conditions (catalyst loading of $2 \mathrm{~g} \mathrm{~L}^{-1}$ with $1000 \mathrm{mg} \mathrm{L}^{-1}$ initial phenol concentration solution at initial $\mathrm{pH}$ of 3 ). After determining the performance of the $\mathrm{Al} / \mathrm{Fe}-\mathrm{PILCs}$ catalyst in each reaction, the used catalyst was recovered by separating the catalyst solids from liquid phase at the end of each catalytic run. Then the solid catalyst was added into $100 \mathrm{~mL}$ of $\mathrm{CaCl}_{2}$ solution (4\%) to remove organics adsorbed on surface of the catalyst and stirred for $120 \mathrm{~min}$ at $25^{\circ} \mathrm{C}$ and then washed with high purity water. The recovered catalysts were oven-dried at $120^{\circ} \mathrm{C}$ for 5 hours, and characterized by PXRD and surface area analyses. The recovered catalyst was then reused for the same reaction under the same conditions.

\section{Results and discussion}

\subsection{Physicochemical characterization}

The surface morphology of the natural bentonite clay and PILCs catalysts samples are shown in ESI (Fig. S2 $\dagger$ ). According to SEM micrographs, the natural bentonite clay as well as the pillared bentonite clay samples showed a tightly packed pattern with rough surface. The EDS results showed the existence of Fe in the sheets of pillared bentonite clay catalysts. The mechanical structure of natural bentonite clay was not destroyed by the pillaring process (also confirmed by the XRD results). Table 1 shows the chemical composition of the natural and pillared bentonite clay samples, as obtained from EDS analysis. The chemical composition results revealed that the natural bentonite clay contained high amounts of oxides of $\mathrm{Si}^{4+}$ and $\mathrm{Al}^{3+}$ with exchangeable interlayer cations such as $\mathrm{Na}^{+}, \mathrm{Mg}^{2+}, \mathrm{Ca}^{2+}, \mathrm{K}^{+}$ and $\mathrm{Fe}^{3+}$. The high content of $\mathrm{Si} / \mathrm{Al}$ indicate the high amount of quartz and muscovite in the starting natural bentonite clay. ${ }^{23}$ However, after modification by pillaring, the $\mathrm{Si} / \mathrm{Al}$ ratio decreased as results of removal of the quartz. The high content of $\mathrm{Na}^{+}$than $\mathrm{Ca}^{2+}$ in the natural bentonite clay might be the indication that the interlamellar cation is sodium, therefore having a high swelling and cationic exchange capacities. ${ }^{24}$ The increase of $\mathrm{Al}^{3+}$ and $\mathrm{Fe}^{3+}$ cations and the decrease of $\mathrm{Na}^{+}, \mathrm{Mg}^{2+}$, $\mathrm{Ca}^{2+}$ and $\mathrm{K}^{+}$exchangeable cations in the pillared bentonite clay

Table 1 Physicochemical characteristics of natural and pillared bentonite clay samples by EDX, CEC and XRD

\begin{tabular}{|c|c|c|c|c|c|c|c|c|c|c|c|}
\hline Sample & $\begin{array}{l}\mathrm{Al} / \mathrm{Fe} \\
\text { ratio }\end{array}$ & $\mathrm{Na}(\%)$ & $\mathrm{Mg}(\%)$ & $\mathrm{Al}(\%)$ & $\mathrm{Si}(\%)$ & K & $\mathrm{Ca}$ & $\mathrm{Fe}$ & $\mathrm{Si} / \mathrm{Al}$ & $\begin{array}{l}\text { CEC } \\
(\mathrm{meq} / 100 \mathrm{~g})\end{array}$ & $d_{001}$ \\
\hline Bentonite & - & 3.73 & 2.29 & 15.31 & 65.09 & 2.39 & 2.09 & 9.10 & 4.25 & 78.6 & 1.24 \\
\hline Al-PILCs & - & 0.96 & 1.24 & 31.98 & 59.14 & 1.82 & 0.27 & 4.55 & 1.85 & 40 & 1.52 \\
\hline Fe-PILCs & - & 0.93 & 1.22 & 13.73 & 52.42 & 1.42 & 0.16 & 30.12 & 3.82 & 27 & 1.56 \\
\hline $\mathrm{Al} / \mathrm{Fe}-\mathrm{PILCs}$ & $1: 3$ & 0.96 & 2.08 & 19.98 & 56.80 & 56.80 & 0.13 & 18.61 & 2.84 & 23 & 1.59 \\
\hline $\mathrm{Al} / \mathrm{Fe}-\mathrm{PILCs}$ & $1: 1$ & 0.97 & 1.35 & 21.88 & 57.19 & 57.19 & 0.15 & 17.01 & 2.61 & 20 & 1.61 \\
\hline $\mathrm{Al} / \mathrm{Fe}-\mathrm{PILCs}$ & $3: 1$ & 0.91 & 1.25 & 20.55 & 57.70 & 57.70 & 0.14 & 17.97 & 2.81 & 21 & 1.69 \\
\hline $\mathrm{Al} / \mathrm{Fe}-\mathrm{PILCs}$ & $6: 1$ & 0.86 & 1.79 & 21.78 & 56.75 & 56.75 & 0.15 & 16.99 & 2.61 & 31 & 1.64 \\
\hline
\end{tabular}


samples confirmed the insertion of the $\mathrm{Al}^{3+}$ and $\mathrm{Fe}^{3+}$ Keggin ion between the bentonite clay sheets.

The cation exchange capacity (CEC) is one of the most significant properties of bentonite clay that is mainly related to the cation adsorption ability and surface functionalization. The CEC of natural and pillared bentonite clay was measured by the ammonium acetate exchange according to the Kjeldahl method and the results obtained are illustrated in Table 3 . The CEC value of natural bentonite clay was about $78.6 \mathrm{meq} / 100 \mathrm{~g}$ which is in good agreement with well-known CEC value of South African natural bentonite clay of $>60 \mathrm{meq} / 100 \mathrm{~g} .{ }^{23}$ As it can be seen in Table 1, the CEC values of single and mixed pillared clays samples shows a decrease (from 78.6 to $21 \mathrm{meq} / 100 \mathrm{~g}$ ) compared to natural bentonite clay, therefore, demonstrating that the exchangeable cations were replaced by $\mathrm{A}^{3+}$ and $\mathrm{Fe}^{3+}$ pillars incorporated into the natural bentonite clay during pillaring process. Moreover, the decrease of CEC of the natural bentonite clay after pillaring suggests the irreversibility of cation exchange process.

The XRD patterns of the natural and pillared bentonite clay are shown in Fig. 1. The XRD results confirm the successful pillaring of the natural bentonite clay material in all cases. Table 1 shows the results of basal spacing $\left(d_{001}\right)$ values of natural and pillared bentonite clay. The $d_{001}$ values of all pillared bentonite clay samples increased after pillaring, which further confirmed the intercalation of the metal oxides pillars into the interlayer space of the bentonite clay. The basal spacing of the mixed metal oxide pillared clays are higher than those of the single metal oxide pillared clays as shown in Table 1. The increased basal spacing observed in the Al-PILCs can be attributed to the size of $\mathrm{Al}$ oligomers $\left[\mathrm{AlO}_{4} \mathrm{Al}_{12}(\mathrm{OH})_{24}\left(\mathrm{H}_{2} \mathrm{O}\right)_{12}\right]_{7}$ that was greater than the Fe oligomer $\mathrm{Fe}_{3}(\mathrm{OH})_{4}{ }^{5+} \cdot{ }^{\mathbf{1 4}}$ The XRD patterns in Fig. 1 show well-defined reflections at 2 theta value of $7.40^{\circ}$ which correspond to $d_{001}$ value of $1.24 \mathrm{~nm}$ which is a typical characteristic peak of natural sodium bentonite clay, revealing that the predominant exchangeable cation could be sodium, as suggested by EDS analysis (see Table 1). Moreover, the natural bentonite clay matrices contain mineral impurities such as quartz, muscovite and calcite. ${ }^{25,26}$ After modification by

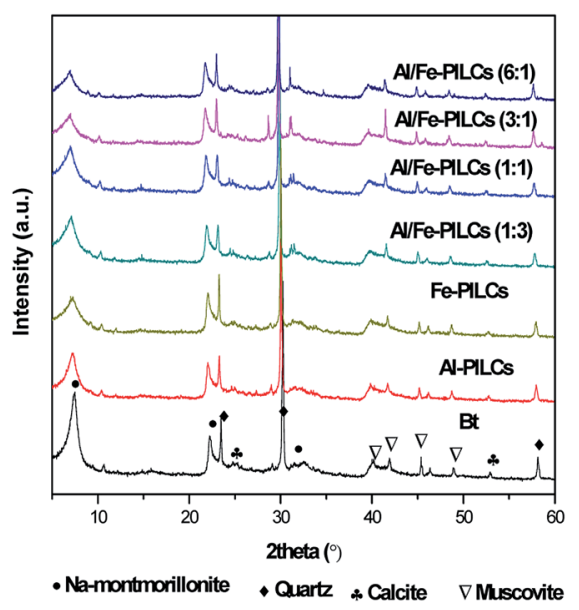

Fig. 1 X-ray diffraction spectra of natural and pillared bentonite samples clays. pillaring with $\mathrm{Al}$ and $\mathrm{Fe}$, the (001) reflections shifted to lower 2 theta values, which resulted in an increase in $d_{001}$ values from $1.24 \mathrm{~nm}$ to $1.69 \mathrm{~nm}$. Meanwhile, no noticeable reflections of any crystalline phase of $\mathrm{Fe}$ oxides in Fe pillared bentonite clay samples are observed, as they would likely show a significantly lesser degree of crystallization. It is noteworthy that the natural bentonite clay structure was not negatively altered after pillaring, since the peaks observed in natural bentonite clay were retained, which is in agreement with the findings reported by Chen et al. ${ }^{27}$ As reported by Jia et al. the ratio of $\mathrm{Al} / \mathrm{Fe}$ influences the size of pillaring, and the sample with $\mathrm{Al} / \mathrm{Fe}$ ratio $3: 1$ displays the highest basal spacing of pillared bentonite clay. ${ }^{28}$ These findings were similar to those reported in the literature for single and mixed metal oxides of $\mathrm{Al}$ and $\mathrm{Fe}$ pillared bentonite clay. ${ }^{\mathbf{1 , 2 9 , 3 0}}$

The $\mathrm{pH}$ point of zero charge $\left(\mathrm{pH}_{\mathrm{zpc}}\right)$ of the catalyst is an important parameter to determine the $\mathrm{pH}$ at which the surface has net electrical neutrality and surface charge plays a main role in the adsorption of ionisable pollutants into catalyst from aqueous solutions. The surface charge results of the natural and pillared bentonite clay used in this study are shown in Fig. 2 . According to the literature and the results obtained in this study the natural bentonite clay displayed negative zeta potential values without an isoelectric point over the entire $\mathrm{pH}$ range (110) studied. ${ }^{23,27,31}$ The $\mathrm{pH}_{\mathrm{zpc}}$ values of Al-PILCs, Fe-PILCs, Al/FePILCs (1:3), Al/Fe-PILCs (1:1), Al/Fe-PILCs (3:1) and Al/FePILCs $(6: 1)$ were found to be $5.4,5.7,3.3,3.4,3.7$ and 4 , respectively, whereas the $\mathrm{pH}_{\text {zpc }}$ value of natural bentonite clay was not observed. The negative zeta potential values of natural bentonite clay can be supported by the fact that bentonite clay particles comprise of a permanent negative charge arising from isomorphous substitution of structural $\mathrm{Si}^{4+}$ by $\mathrm{Al}^{3+}$ and $\mathrm{OH}$ groups $\mathrm{pH}$ dependent charge at the edges of the bentonite clay particles. Therefore, the obtained decrease in negative zeta potential from -28.6 to $-17.5 \mathrm{mV}$ with increasing $\mathrm{H}^{+}$ions in the solution can be attributed to $\mathrm{pH}$ dependent charge. However, after pillaring of natural bentonite clay with $\mathrm{Al}^{3+}$ and $\mathrm{Fe}^{3+}$, the obtained pillared clay solid materials had positive zeta potential values at $\mathrm{pH}>3.3$ and $\mathrm{pH}<5.7$. The positive and negative zeta potential values of pillared clays at acidic and basic $\mathrm{pH}$, respectively, can be attributed to predominant pillared

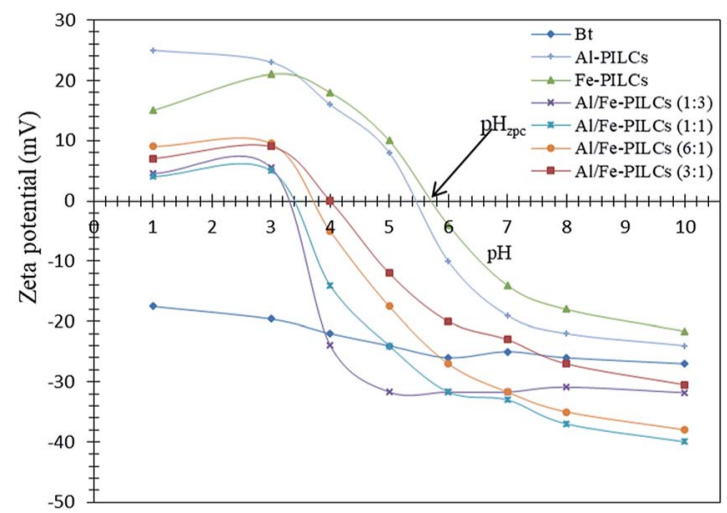

Fig. 2 Zeta potentials for different $\mathrm{pH}$ values of natural and pillared bentonite clay. 

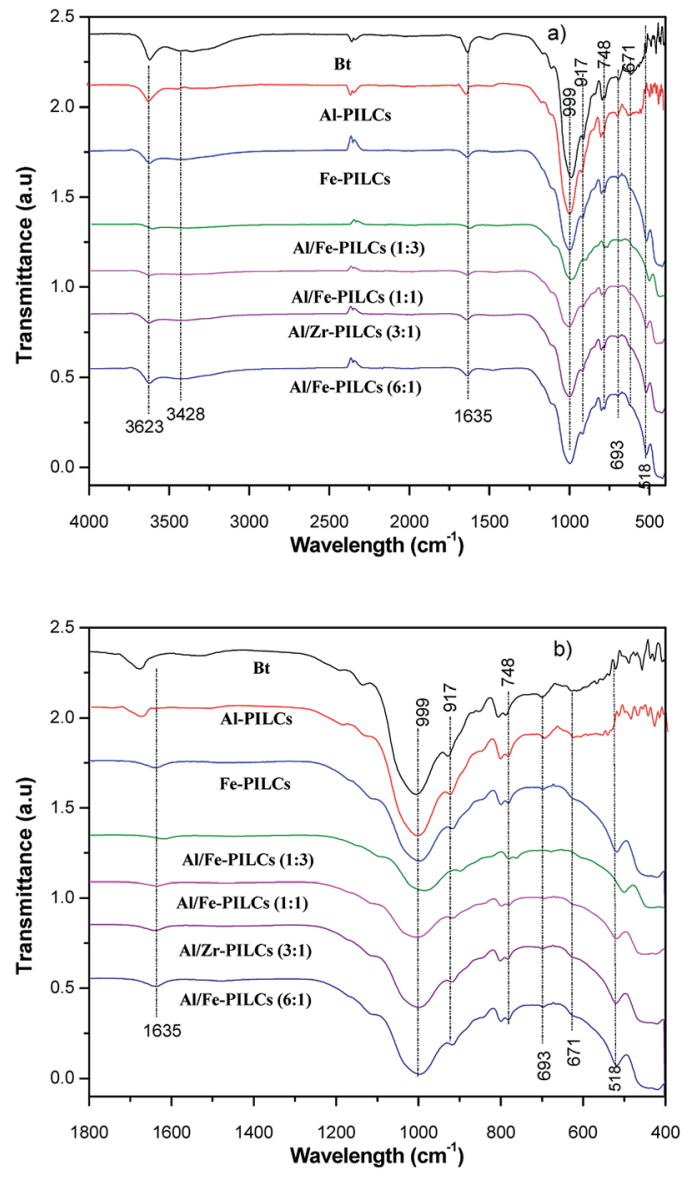

Fig. 3 FTIR spectra of natural (Bt) and pillared bentonite clay catalysts; (a) wide range wavelength and (b) low range wavelength.

bentonite clay surface species. For example $\mathrm{Fe}(\mathrm{II}, \mathrm{III}) \mathrm{OH}_{2}{ }^{+}$and $\mathrm{Al}(\mathrm{III}) \mathrm{H}_{2}{ }^{+}$are predominant species at acidic $\mathrm{pH}$ whereas $\mathrm{Fe}(\mathrm{II}, \mathrm{III})$ $\mathrm{O}^{-}$and $\mathrm{Al}(\mathrm{OH})_{4}{ }^{-}$are predominant bentonite pillared clay surface species at basic $\mathrm{pH}$. The $\mathrm{pH}_{\mathrm{zpc}}$ values of single metal oxide pillared clay were found to be lower compared to mixed metal oxides pillared clay. This can be attributed to the fact that the mixed oxides of $\mathrm{Al} / \mathrm{Fe}$ polyoxycations are presented as $\left\{\left[\mathrm{Al}_{x} \mathrm{Fe}_{y}(\mathrm{OH})_{z}\left(\mathrm{H}_{2} \mathrm{O}\right)_{n}\right]^{(3 x+3 y-z)^{+}}\right\}$, which is a predominant species on the surface of $\mathrm{Al} / \mathrm{Fe}-\mathrm{PILCs}$ and results in an increase of hydroxyl groups. This then causes a decrease of positive charges and $\mathrm{pH}_{\mathrm{zpc}}$ values. The significance of these zeta potential values is that conversion of phenol is expected to be flexible below the obtained $\mathrm{pH}_{\mathrm{zpc}}$ values of pillared clays since the net positively charged of pillared clays is likely to attract the phenol anions.

Shown in Fig. 3 is the FTIR analysis of natural and pillared bentonite clay. It can be seen from the FTIR spectra that there are no significant differences between the FTIR spectra of the natural and pillared bentonite clays, suggesting that the structure of natural bentonite clay was not affected by pillaring process. These findings are in agreement with both the SEM and XRD analysis results in this study. However, decreases of the peaks at $3623 \mathrm{~cm}^{-1}$ and in the range of 400 to $999 \mathrm{~cm}^{-1}$, were observed for bentonite pillared clay catalysts, with more peak decrease in the mixed metal oxides compared to single metal oxides pillared catalysts. This can be attributed to the interactions between $\mathrm{Al}, \mathrm{Fe}$ or $\mathrm{Al} / \mathrm{Fe}$ mixed polyoxocations with $\mathrm{Si}-\mathrm{O}$ group in the siloxane layers (silica tetrahedron plates) and Al-OH group in the alumina octahedral layers. ${ }^{32,33}$ The absorption band located at $3623 \mathrm{~cm}^{-1}$ is ascribed to $\mathrm{O}-\mathrm{H}$ stretching vibrations of non-hydrogen-bonded water region while the relatively weak absorption bands at $3428 \mathrm{~cm}^{-1}$ is also attributed to $\mathrm{O}-\mathrm{H}$ stretching vibrations but of hydrogen-bonded water region. ${ }^{34}$ The peak at $1635 \mathrm{~cm}^{-1}$ can be assigned to the $\mathrm{H}-\mathrm{O}-\mathrm{H}$ bending vibration. ${ }^{34}$ The strong intense peak near $999 \mathrm{~cm}^{-1}$ corresponds to the in-plane $\mathrm{Si}-\mathrm{O}-\mathrm{Si}$ stretching vibrations. ${ }^{28}$ The absorption band at $917 \mathrm{~cm}^{-1}$ is ascribed to $\mathrm{Al}-\mathrm{O}(\mathrm{OH})-\mathrm{Al}$ deformation, and the peaks situated at $518 \mathrm{~cm}^{-1}, 671 \mathrm{~cm}^{-1}$, $693 \mathrm{~cm}^{-1}$ and $748 \mathrm{~cm}^{-1}$ corresponds to the deformation of Si$\mathrm{O}-\mathrm{Fe}, \mathrm{Si}-\mathrm{O}-\mathrm{Al}$, coupled $\mathrm{Al}-\mathrm{O}$ and $\mathrm{Si}-\mathrm{O}$ out of plane stretching vibration and $\mathrm{Si}-\mathrm{O}-\mathrm{Mg}$, respectively. ${ }^{28,34}$ The absorption bands corresponding to $\mathrm{Fe}-\mathrm{O}-\mathrm{Fe}$ vibration of Fe-bentonite were not detected. Similar findings were reported by Chen and Zhu who reported that this might be due to the characteristic stretching vibrations of natural bentonite clay mineral. ${ }^{35}$

The nitrogen adsorption-desorption measurements were investigated on both natural and pillared clays in order to determine porosity and BET surface area. The corresponding parameters such as BET surface area, total pore volume, micropores volume and pore diameter are summarised in Table 2. The obtained BET surface area and total pore volume of PILCs are much higher compared to natural bentonite clay. This indicates that the modification of natural bentonite clay by pillaring results in a significant increase in porosity and BET surface area. The BET surface areas of the mixed metal catalysts are higher than those of the single metal catalysts, which suggest that introduction of second metal ions greatly

Table 2 Surface properties of prepared catalysts and raw bentonite clay

\begin{tabular}{lllll}
\hline Sample & Al/Fe ratio & $S_{\text {BET }}{ }^{a}\left(\mathrm{~m}^{2} \mathrm{~g}^{-1}\right)$ & $V_{\text {pore }}^{b}\left(\mathrm{~cm}^{3} \mathrm{~g}^{-1}\right)$ & $V_{\text {mic }^{c}\left(\mathrm{~cm}^{3} \mathrm{~g}^{-1}\right)}$ \\
\hline Bentonite & - & 61 & 0.11 & 0.089 \\
Al-PILCs & - & 140 & 0.30 & 0.102 \\
Fe-PILCs & - & 147 & 0.32 & 0.099 \\
Al/Fe-PILCs & $1: 3$ & 175 & 0.34 & 0.110 \\
Al/Fe-PILCs & $1: 1$ & 190 & 0.35 & 0.111 \\
Al/Fe-PILCs & $3: 1$ & 200 & 0.37 & 0.113 \\
Al/Fe-PILCs & $6: 1$ & 169 & 0.33 & 0.105
\end{tabular}

${ }^{a}$ Specific surface area $\left(S_{\mathrm{BET}}\right) .{ }^{b}$ Total pore volume at $P / P^{0} \sim 0.99 .{ }^{c}$ Micropore volume. ${ }^{d}$ Pore diameter. 
improved the BET surface area and porosity. The increase in the BET surface areas of pillared natural bentonite samples may be attributed to the increase of micropores volume and enlarged total pore volume of micropores. The pore diameter of mixed metal composite catalysts greatly decreased compared to single metal catalysts, which positively impact the catalytic properties of mixed composite PILCs.

The thermograms and their derivative curves for both natural bentonite and the pillared bentonite clay samples carried out between 35 and $900{ }^{\circ} \mathrm{C}$ are shown in Fig. 4 . As can be seen in Fig. 4, thermal analysis (TGA/DTG) of the natural bentonite clay and pillared bentonite clay samples showed a similar thermal behaviour, in which the mass loss for all the samples occurs in three stages. All the Al/Fe-PILCs samples display relatively small weight losses even at high temperatures compared with the $\mathrm{Al}$ and Fe-PILCs as well as the natural clay. As shown in Fig. 4 the TGA curves show an initial weight loss of $2.2 \%, 2.1 \%, 1.9 \%, 0.8 \%, 0.6 \%, 0.5 \%$ and $0.3 \%$ for natural bentonite, Al-PILCs, Fe-PILCs, Al/Fe-PILCs (1:3), Al/Fe-PILCs (1:1), Al/Fe-PILCs $(3: 1)$ and Al/Fe-PILCs (6:1), respectively, starting at $38{ }^{\circ} \mathrm{C}$ and ending at $156{ }^{\circ} \mathrm{C}$. The major decomposition occurred above $554{ }^{\circ} \mathrm{C}$ and total weight loss at $900{ }^{\circ} \mathrm{C}$ was $23.5 \%, 18.1 \%, 12.3 \%, 12.0 \%, 11.8 \%, 10.5 \%$ and $9 \%$, respectively for natural bentonite, Al-PILCs, Fe-PILCs, Al/Fe-PILCs (1:3), Al/Fe-PILCs (1:1), Al/Fe-PILCs $(3: 1)$ and Al/Fe-PILCs
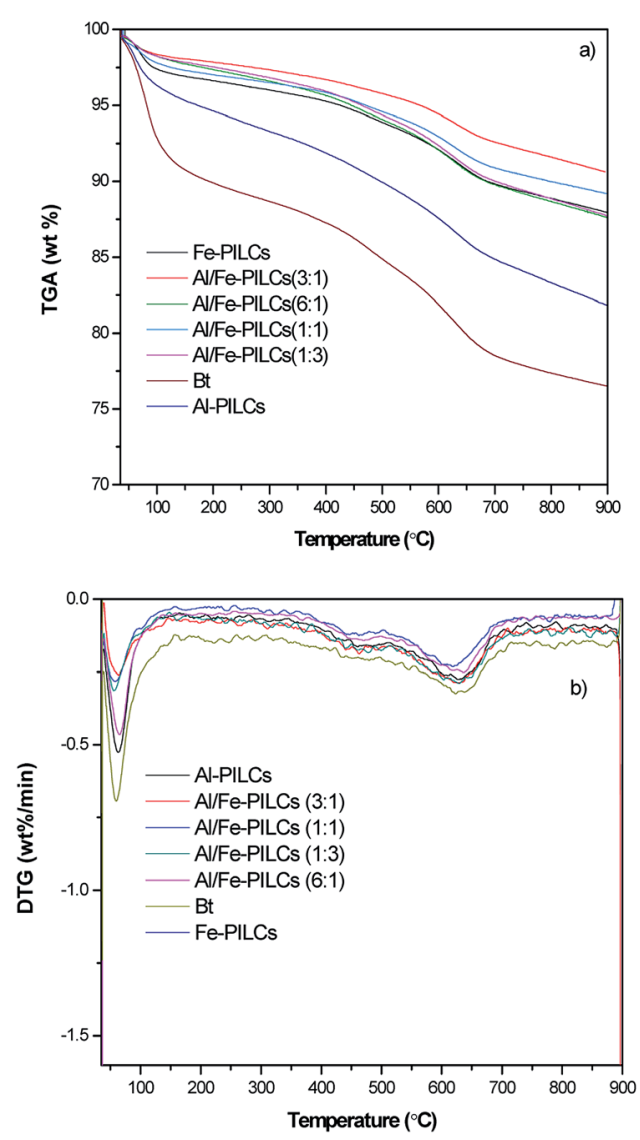

Fig. 4 Thermogravimetric analyses (TGA) (a) and their derivative plots (DTG) (b) for natural and pillared bentonite clay samples.
(6:1). This can be attributed to the fact that the $\mathrm{Al}$ and $\mathrm{Fe}$ polycations introduced in the layers of the clay form thermally stable oxides during the heat treatment in the pillaring process which prevents the collapse of the clay layers. ${ }^{28,36}$ The derivative plot of the thermal gravimetric analysis (DTG) showed three peaks for natural bentonite clay, Al-PILCs, Fe-PILCs and $\mathrm{Al} / \mathrm{Fe}-$ PILCs samples in the range of $36-150{ }^{\circ} \mathrm{C}, 388-487{ }^{\circ} \mathrm{C}$ and $576-721{ }^{\circ} \mathrm{C}$. The peaks observed can be attributed to oxidation state of $\mathrm{Al}$ or $\mathrm{Fe}$ polycations used during the pillaring process. ${ }^{28}$ For example oxidation state of $\mathrm{Fe}$ are $\mathrm{Fe}^{2+}, \mathrm{Fe}^{3+}$ and $\mathrm{Fe}^{6+}$, which resulted in three peaks. The first peak was due to the loss of physical adsorbed water molecules from the interlayer space. ${ }^{29}$ The second small peak corresponds to the structural dehydroxylation of the clay mineral. ${ }^{37}$ Finally the third step is attributed to the thermal decomposition of the layered pattern of the bentonite clay. ${ }^{30,38}$ This is consistent with the literature where there are reports of the thermal stability of the bentonite pillared clays up to $650{ }^{\circ} \mathrm{C} .{ }^{39}$

\subsection{Catalytic wet air oxidation of phenol}

The performance of the catalyst samples in the catalytic wet air oxidation of phenol are shown in Fig. 5. The conversion of phenol was negligible in the absence of catalyst, showing that phenol is extremely stable under non-catalysed reaction conditions. The conversion of phenol was very low $(8 \%)$ in the presence of natural bentonite clay due to the absence of catalytic active sites and also due to highly negative charge of natural bentonite clay (as shown in Fig. 2) resulting in repulsion between its particles and negatively charged phenol. However, the pillared clay catalysts yield a very high phenol conversion, with the Al-PILCs and Fe-PILCs giving 74 and 85\% conversion respectively over reaction time of $120 \mathrm{~min}$ and complete conversion at $180 \mathrm{~min}$. The $\mathrm{Al} / \mathrm{Fe}-\mathrm{PILCs}$ showed higher activities with total conversion of phenol occurring at $120 \mathrm{~min}$ of reaction time. The order of the activities of the catalysts is Al-PILCs $<\mathrm{Fe}$ PILCs < Al/Fe-PILCs $(6: 1)<\mathrm{Al} / \mathrm{Fe}-$ PILCs $(1: 3)<\mathrm{Al} / \mathrm{Fe}-\mathrm{PILCs}$ $(1: 1)<\mathrm{Al} / \mathrm{Fe}-\mathrm{PILCs}(3: 1)$ with the most active catalyst being the Al/Fe-PILCs with a $\mathrm{Al}: \mathrm{Fe}$ molar ratio of $3: 1$. Furthermore, TOC removal in the phenol oxidation by adsorption and in the absence of a catalyst (WAO) was negligible. In contrast, using pillared bentonite clay catalysts, the removal of TOC was significantly increased, 55\%, 58\%, 65\%, 68\%, 75\% and $80 \%$ being achieved in less than $180 \mathrm{~min}$ with Al-PILCs, Fe-PILCs, Al/ Fe-PILCs (6 : 1), Al/Fe-PILCs (1 : 3), Al/Fe-PILCs (1:1) and Al/FePILCs $(3: 1)$, respectively. This observed trend in the performance of the catalysts can be attributed to the fact that pillaring of the clay imparts improved surface electrical properties as well as new functional groups in the clay. The zeta potentials of all the pillared clay samples were positive at $\mathrm{pH}$ below $\mathrm{pH}_{\mathrm{zpc}}$ which indicate a positively charged surface of pillared clay samples. Therefore, the positive charge surface promotes the adsorption of phenol, which consequently increases oxidation of phenol on the catalyst surface. The larger BET surface area of the pillared clay samples also provides more active sites for oxidation reaction of phenol. The catalytic results show promise in the use of pillared clays as catalysts in catalytic wet oxidation reaction 

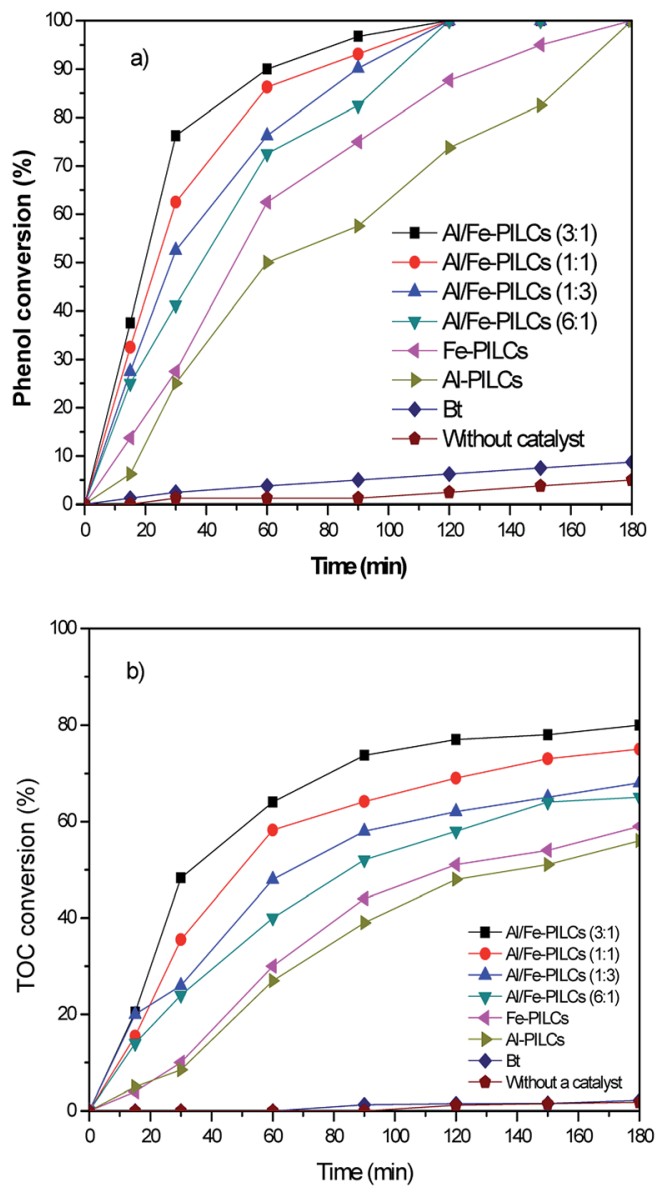

Fig. 5 Phenol (a) and TOC (b) conversions in the CWAO reaction of phenol over the natural and pillared bentonite clay samples (experimental conditions: $200 \mathrm{~mL}$ of reaction solution, $1000 \mathrm{mg} \mathrm{L}^{-1}, 0.4 \mathrm{~g}$ of catalyst, $\mathrm{pH} 3.0,10$ bar and $100^{\circ} \mathrm{C}$ ).

especially as the reaction here is carried out under mild conditions.

Table 3 summarizes a comparison of the performance of Al/ Fe-PILCs catalyst in this study with some representative catalysts discussed in the literature for the CWAO of phenol in wastewater. To date very few published studies focused on the use of Al/Fe-PILCs in CWAO, ${ }^{1,3}$ most of studies widely reported the use of Al/Fe-PILCs with costly hydrogen peroxide $\left(\mathrm{H}_{2} \mathrm{O}_{2}\right)$ oxidant. ${ }^{13-16,40}$ Therefore, the Al/Fe-PILCs in this study was also compared with other developed CWAO heterogeneous catalysts such as carbon materials (reduced graphene oxides, multiwalled carbon nanotubes...), noble metals catalysts ( $\mathrm{Ru}, \mathrm{Pt} .$. ) and transition metal oxides $\left(\mathrm{MnO}_{2}, \mathrm{Fe}_{2} \mathrm{O}_{3} \ldots\right)^{41-43}$ As shown in Table 3, complete phenol oxidation and TOC removals can be accomplished at relatively faster oxidation rates, however, at high reaction conditions are temperatures $\left(>100{ }^{\circ} \mathrm{C}\right)$ and pressures (>10 bar); these severe reaction conditions are strongly influenced by lack of robust catalysts which can be used under mild conditions. ${ }^{44}$ In order to make CWAO process feasible at industrial scale, in the last decade a lot of attention has been paid to developing heterogeneous catalysts that can be used under mild conditions to reduce the costs for CWAO process. The Al/Fe-PILCs catalysts developed in this study show good catalytic performance under mild reaction conditions compared to most of the listed catalysts in Table 3. In generally the use of natural clay and transitional metal oxides as active phase reduces the preparation cost of the synthesized pillared clay catalysts in the present study.

According to the literature CWAO of phenol by hydroxyl radical takes place involving a free radical chain reaction. ${ }^{45,46}$ Timofeeva et al. reported that the important step in the phenol oxidation in the presence of heterogeneous Fe-containing system is a formation of strong oxidation species such as $\mathrm{HO}^{*}$ radical compared to unreactive $\mathrm{O}_{2}{ }^{-}$and $\mathrm{HO}_{2}{ }^{-}$radicals. The $\mathrm{HO}^{\circ}$ radical could rapidly oxidize the phenol through direct conversion to $\mathrm{CO}_{2}$ and $\mathrm{H}_{2} \mathrm{O}$ and via formation of aromatic intermediates such as hydroquinone and pyrocatechol. ${ }^{47,48}$ Further hydroxylation of formed aromatics intermediates led to the formation of benzoquinone which transform into short-chain carboxylic acids such as maleic, malonic, oxalic, formic and acetic acids. ${ }^{49}$ The intermediates of phenol oxidation were analyzed by HPLC and identified by comparison with selected commercial standards in this study. Fig. 6 shows the evolution of the intermediates and concentration profiles of phenol in the CWAO of phenol over Al/Fe-PILCs $(\mathrm{Al}: \mathrm{Fe}=3: 1)$ as catalyst. The analysis of HPLC data detected the generation of intermediates such as hydroquinone and

Table 3 Performance comparison of various CWAO heterogeneous catalysts for phenol oxidation

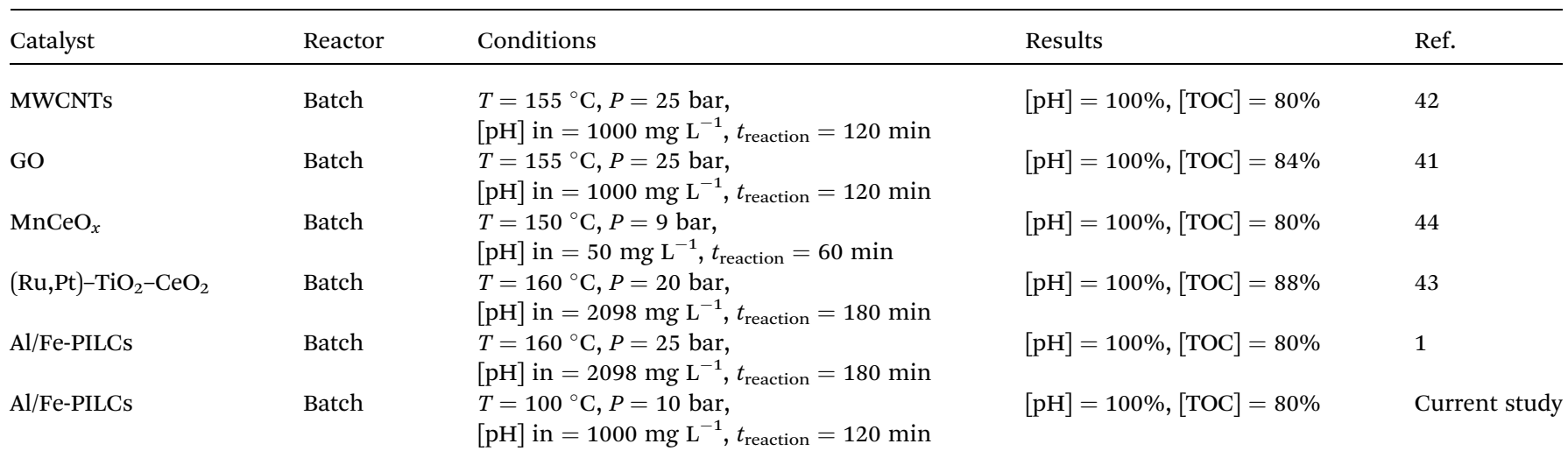




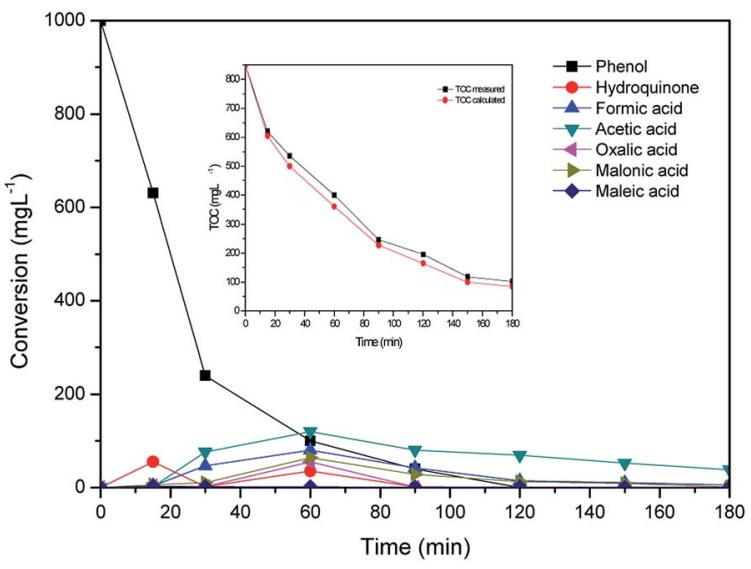

Fig. 6 Evolution of phenol and intermediates in the CWAO of phenol over the Al/Fe-PILCs $(3: 1)$.

short chain carboxylic acids (acetic and maleic acids) after $15 \mathrm{~min}$ of phenol oxidation reaction. At $60 \mathrm{~min}$ reaction time the concentration of the intermediates (maleic, acetic, formic, oxalic, malonic acids, as main intermediates, benzoquinone and pyrocatechol, as traces, below $10 \mathrm{mg} \mathrm{L}^{-1}$ ) increase as phenol gets oxidized. However, after $120 \mathrm{~min}$ of the reaction the concentration of the intermediates becomes insignificant. The detected intermediates during the reaction did not accumulate in large quantities in the phenol reaction solution as they are rapidly oxidised by highly active hydroxyl radicals to form $\mathrm{CO}_{2}, \mathrm{H}_{2} \mathrm{O}$ and less harmful intermediates such as acetic acid. This behaviour can be attributed to the resistance of lowmolecular-weight short chain carboxylic acids to CWAO, consistent with previous studies. ${ }^{49,50}$ The $\mathrm{Al} / \mathrm{Fe}$ pillared bentonite clay catalyst exhibited good catalytic activity in the CWAO of phenol, since complete oxidation of phenol was achieved with formation of less harmful intermediates. The content of these carboxylic acids intermediates can be calculated by TOC concentration and about $80 \%$ TOC conversion was obtained. The actual measured TOC and the calculated TOC by the identified intermediates were compared and results are shown in Fig. 6 (inset). As shown in Fig. 6 (inset), the two curves of TOC conversion with reaction time can be well fitted together, suggesting that the main intermediates are detected by HPLC in the CWAO of phenol in aqueous solution.

\subsection{Catalyst stability and reusability}

For practical applications, it is important to determine the stability and reusability of catalysts. The stability and reusability of the Al/Fe-PILCs (with $\mathrm{Al} / \mathrm{Fe}$ ratio of $3: 1$ ) catalyst against metal leaching during the reaction was investigated in this work. To study the leaching of $\mathrm{Fe}^{3+}$ metal cations from pillared clay catalyst, concentration of total $\mathrm{Fe}^{3+}$ ions in the solution after $120 \mathrm{~min}$ of reaction time were measured and the results presented in Table 4 . The catalyst was reused seven times to investigate its reusability. The results indicate that the concentration of $\mathrm{Fe}^{3+}$ ions leached in the solution after the reaction was $\leq 0.295 \mathrm{mg} \mathrm{L}^{-1}$ which is below the World Health Organization (WHO) maximum permissible level $\left(0.3 \mathrm{mg} \mathrm{L}^{-1}\right)$ in drinking water after seven consecutive catalytic runs. ${ }^{51}$ The results demonstrate that the pillared clay catalyst has good stability towards leaching of $\mathrm{Fe}^{3+}$ after the phenol oxidation reaction, since the leaching of $\mathrm{Fe}^{3+}$ was found to be negligible. The observed leaching could be attributed to the iron sites decorating the bentonite clay pillars, whereas the metal incorporated within the structure of the mixed bentonite clay pillars has been thought to be the most active in the catalytic wet air oxidation of phenol. ${ }^{8}$ This confirms that the pillaring cations were well incorporated in the pillar structure of the catalyst. After seven consecutive reaction runs the phenol removal slightly decreased from 100 to $85 \%$ in 120 min reaction time. The slight decrease in catalytic activity can be attributed to the deposition of phenol on the catalyst surface during the reaction, which results in the blocking of the channels and, thus, to a decrease in the number of available active sites. ${ }^{2}$ No significant decrease in surface area as well as in the $d_{100}$ basal spacing of the catalyst is observed with each reuse. However, the TOC conversion decrease significantly from $80 \%$ to $50 \%$ with recycling times, suggesting that more hydroxylation instead of minimization of phenol took place with increasing consecutive reaction runs. Therefore, as shown in Table 3 three consecutive reaction runs for the Al/Fe-PILCs catalyst were attainable to achieve complete removal of phenol and $71 \%$ conversion of TOC in our studies. These results are in agreement with those published by Sassi et al. CWAO of phenol using Al/Fe-PILCs. ${ }^{1}$ The oxidation of phenol was reported to be $95 \%$, while $80 \%$ of TOC removal was obtained at $160{ }^{\circ} \mathrm{C}$ under 25 bar of pure oxygen after $180 \mathrm{~min}$ of reaction. Less than $0.7 \mathrm{mg} \mathrm{L}^{-1}$ of initial Fe species was leached out during the consecutive re-use of the catalyst, indicating that the Fe species were quite stable.

Table 4 Stability, leaching and basal spacing features of reused Al/Fe-PILCs catalyst in the removal of phenol and TOC over optimum conditions

\begin{tabular}{|c|c|c|c|c|}
\hline First use & 100 & 80 & 0.175 & 1.69 \\
\hline Re-use 2 & 100 & 71 & 0.214 & 1.65 \\
\hline Re-use 3 & 96 & 65 & 0.221 & 1.65 \\
\hline Re-use 4 & 91 & 57 & 0.263 & 1.64 \\
\hline
\end{tabular}




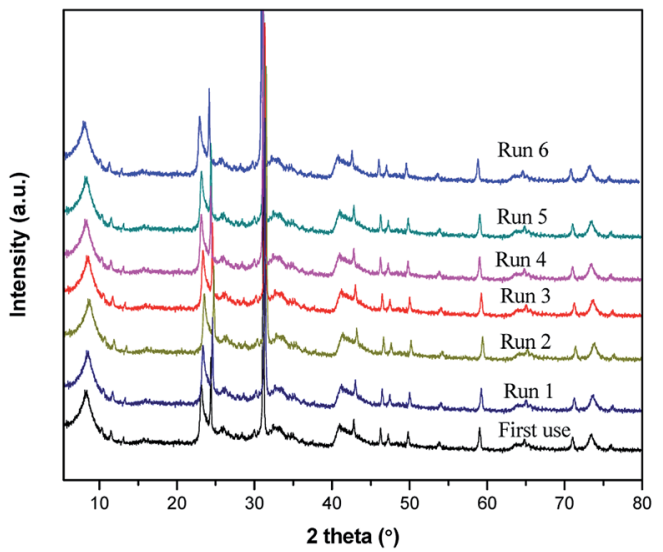

Fig. 7 PXRD patterns of the fresh and reused Al/Fe-pillared clay samples.

\subsection{Structural studies of the catalyst after each catalytic run}

The spent catalysts were characterized by PXRD to determine the effect of the catalyst re-use on its structure and morphology. Fig. 7 demonstrates results for structural stability of the catalyst after each consecutive catalytic run. After six reuse of the catalyst, its characteristic PXRD peaks are maintained, while there is gradual decrease in the basal spacing. Therefore, our preparation method which employs the use of ultrasonic treatment during the aging and intercalation steps results in a highly stabilized $\mathrm{Fe}^{3+}$ species in the pillared clay matrix.

\section{Conclusions}

Natural bentonite clay was successfully pillared with $\mathrm{Al}, \mathrm{Fe}$ and $\mathrm{Al} / \mathrm{Fe}$ polycations using ultrasonic treatment during the aging and the intercalation stages and tested for CWAO of phenol in aqueous solutions. This method resulted in a significant decrease in the consumption of water as well as synthesis time and the catalyst synthesis is performed at room temperature. The PXRD demonstrated an increase in the basal spacing up to $1.69 \mathrm{~nm}$ with a high thermal stability. The textual properties show an increase in BET surface area indicating that $\mathrm{Al} / \mathrm{Fe}$ polycations inserted into the bentonite clay plays a crucial in increasing surface area. HRSEM confirms that this methodology allows interaction of $\mathrm{Al} / \mathrm{Fe}$ polycations with the tetrahedral sheets of the bentonite clay, without destroying the structure of the clay. The pillared clay catalysts were found to completely oxidize phenol and $80 \%$ conversion of TOC in aqueous solution under mild conditions showing the potential of these catalysts to be used in removal of organic compounds from industrial wastewater streams. The analysis of intermediate products revealed the presence of hydroquinone, pyrocatechol, benzoquinone and oxalic, formic, malonic, oxalic, malonic and maleic acids. The Al/Fe-PILCs catalyst could be used in four consecutive reaction runs without significant loss of phenol catalytic activity and $65 \%$ conversion of TOC. Therefore, $\mathrm{Al} / \mathrm{Fe}-\mathrm{PILCs}$ catalysts were found to be promising catalysts for CWAO of phenol in aqueous solutions.

\section{Conflicts of interest}

There are no conflicts to declare.

\section{Acknowledgements}

The authors wish to acknowledge financial support from the National Research Foundation (NRF)/Department of Science and Technology (DST) of South Africa under Professional Development Programme (PDP) Project No. 96719 and Mineral Science Council of South Africa (Mintek) under CWO of Wastewater Project No. ADR31803.

\section{References}

1 H. Sassi, G. Lafaye, H. Ben Amor, A. Gannouni, M. R. Jeday and J. Barbier, Front. Environ. Sci. Eng., 2018, 12, 2.

2 J. Guo and M. Al-Dahhan, Appl. Catal., A, 2006, 299, 175-184.

3 N. Ksontini, W. Najjar and A. Ghorbel, J. Phys. Chem. Solids, 2008, 69, 1112-1115.

4 A. Olaya, S. Moreno and R. Molina, Catal. Commun., 2009, 10, 697-701.

5 A. Olaya, G. Blanco, S. Bernal, S. Moreno and R. Molina, Appl. Catal., B, 2009, 93, 56-65.

6 S. Mnasri-Ghnimi and N. Frini-Srasra, Appl. Clay Sci., 2014, 88-89, 214-220.

7 J. Baloyi, T. Ntho and J. Moma, RSC Adv., 2018, 8, 5197-5211.

8 J. Herney-Ramirez, M. A. Vicente and L. M. Madeira, Appl. Catal., B, 2010, 98, 10-26.

9 A. Olaya, S. Moreno and R. Molina, Appl. Catal., A, 2009, 370, 7-15.

10 M. N. Timofeeva, S. T. Khankhasaeva, Y. A. Chesalov, S. V Tsybulya, V. N. Panchenko and E. T. Dashinamzhilova, Appl. Catal., B, 2009, 88, 127-134.

11 Y.-S. Shin, S.-G. Oh and B.-H. Ha, Korean J. Chem. Eng., 2003, 20, 77-82.

12 A. Gil, L. M. Gandía and M. A. Vicente, Catal. Rev., 2000, 42, 145-212.

13 J. H. Ramírez, L. A. Galeano, G. Pinchao, R. A. Bedoya and A. Hidalgo, J. Environ. Chem. Eng., 2018, 6, 2429-2441.

14 N. R. Sanabria, M. A. Centeno, R. Molina and S. Moreno, Appl. Catal., A, 2009, 356, 243-249.

15 A. Pérez, M. A. Centeno, J. A. Odriozola, R. Molina and S. Moreno, Catal. Today, 2008, 133-135, 526-529.

16 C. B. Molina, J. A. Casas, J. A. Zazo and J. J. Rodríguez, Chem. Eng. J., 2006, 118, 29-35.

17 E. Ruiz-Hitzky and P. Aranda, J. Sol-Gel Sci. Technol., 2014, 70, 307-316.

18 F. Tomul, Appl. Clay Sci., 2016, 120, 121-134.

19 F. Tomul, Chem. Eng. J., 2012, 185-186, 380-390.

20 F. Tomul, Ind. Eng. Chem. Res., 2011, 50, 7228-7240.

21 F. Tomul and S. Balci, Appl. Clay Sci., 2009, 43, 13-20.

22 P. Tepmatee and P. Siriphannon, Mater. Res. Bull., 2013, 48, 4856-4866.

23 V. Masindi, M. W. Gitari, H. Tutu and M. DeBeer, Journal of Water Process Engineering, 2015, 8, 227-240. 
24 M. Vhahangwele and G. W. Mugera, J. Environ. Chem. Eng., 2015, 3, 2416-2425.

25 J. E. Aguiar, J. A. Cecilia, P. A. S. Tavares, D. C. S. Azevedo, E. R. Castellón, S. M. P. Lucena and I. J. Silva, Appl. Clay Sci., 2017, 135, 35-44.

26 J. Li, M. Hu, S. Zuo and X. Wang, Curr. Opin. Chem. Eng., 2018, 20, 93-98.

27 S. Chen, Y. Wu, G. Li, J. Wu, G. Meng, X. Guo and Z. Liu, Appl. Clay Sci., 2017, 136, 103-111.

28 H. Jia, S. Zhao, X. Zhou, C. Qu, D. Fan and C. Wang, Arch. Environ. Prot., 2017, 43(3), 82-90.

29 B. González, R. Trujillano, M. A. Vicente, A. Gil, V. N. Panchenko, E. A. Petrova and M. N. Timofeeva, Appl. Clay Sci., 2017, 146, 388-396.

30 P. Cañizares, J. L. Valverde, M. R. S. Kou and C. B. Molina, Microporous Mesoporous Mater., 1999, 29, 267-281.

31 S. Türker, F. Yarza, R. M. T. Sánchez and S. Yapar, Colloids Surf., A, 2017, 520, 817-825.

32 J. Manjanna, T. Kozaki and S. Sato, Appl. Clay Sci., 2009, 43, 208-217.

33 J. Zhou, P. Wu, Z. Dang, N. Zhu, P. Li, J. Wu and X. Wang, Chem. Eng. J., 2010, 162, 1035-1044.

34 S. Kouraichi, M. El-Hadi Samar, M. Abbessi, H. Boudouh and A. Balaska, Catal. Sci. Technol., 2015, 5, 1052-1064.

35 J. Chen and L. Zhu, Sep. Purif. Technol., 2009, 67, 282-288.

36 T. Mishra, in Pillared Clays and Related Catalysts, ed. A. Gil, S. A. Korili, R. Trujillano and M. A. Vicente, Springer New York, New York, NY, 2010, pp. 99-128.

37 H. J. Chae, I.-S. Nam, S. W. Ham and S. B. Hong, Catal. Today, 2001, 68, 31-40.
38 D. L. Guerra, C. Airoldi, V. P. Lemos and R. S. Angélica, J. Hazard. Mater., 2008, 155, 230-242.

39 M. El Miz, S. Salhi, I. Chraibi, A. El Bachiri, M. Fauconnier and A. Tahani, Open J. Phys. Chem., 2014, 4, 98-116.

40 S. Zhou, C. Zhang, X. Hu, Y. Wang, R. Xu, C. Xia, H. Zhang and Z. Song, Appl. Clay Sci., 2014, 95, 275-283.

41 S. Yang, Y. Cui, Y. Sun and H. Yang, J. Hazard. Mater., 2014, 280, 55-62.

42 S. Yang, X. Wang, H. Yang, Y. Sun and Y. Liu, J. Hazard. Mater., 2012, 233-234, 18-24.

43 A. E. de los Monteros, G. Lafaye, A. Cervantes, G. Del Angel, J. Barbier Jr and G. Torres, Catal. Today, 2015, 258, 564-569.

44 F. Arena, C. Italiano and L. Spadaro, Appl. Catal., B, 2012, 115-116, 336-345.

45 R. R. Zapico, P. Marín, F. V Díez and S. Ordóñez, J. Environ. Chem. Eng., 2017, 5, 2570-2578.

46 F. Stüber, J. Font, A. Fortuny, C. Bengoa, A. Eftaxias and A. Fabregat, Top. Catal., 2005, 33, 3-50.

47 A. Santos, P. Yustos, A. Quintanilla, S. Rodríguez and F. García-Ochoa, Appl. Catal., B, 2002, 39, 97-113.

48 A. Quintanilla, J. A. Casas, A. F. Mohedano and J. J. Rodríguez, Appl. Catal., B, 2006, 67, 206-216.

49 G. Yang, H. Chen, H. Qin, X. Zhang and Y. Feng, Can. J. Chem. Eng., 2017, 95, 1518-1525.

50 A. Eftaxias, J. Font, A. Fortuny, J. Giralt, A. Fabregat and F. Stüber, Appl. Catal., B, 2001, 33, 175-190.

51 D. Pittet, B. Allegranzi and J. Boyce, Infect. Control Hosp. Epidemiol., 2009, 30, 611-622. 